\title{
ANÁLISE DA MORFOMETRIA E DO USO E COBERTURA DA TERRA DA BACIA HIDROGRÁFICA DO RIO MOCAJUBA, ZONA COSTEIRA AMAZÔNICA
}

\author{
Jones Remo Barbosa Vale ${ }^{1}$ \\ Letícia Soares da Costa² \\ Márcia Aparecida da Silva Pimentel ${ }^{3}$
}

Resumo: A bacia hidrográfica do rio Mocajuba está localizada no setor leste da zona costeira amazônica e sua área abrange quatro municípios paraenses. Este trabalho objetiva fazer uma análise da morfometria e do uso e cobertura da Terra da bacia em estudo. A metodologia se baseia no levantamento de parâmetros geométricos, de relevo e drenagem, e na classificação de uma imagem de satélite Landsat 8 do ano de 2019. Os resultados demonstram que a bacia em estudo tem uma área de $329,69 \mathrm{~km}^{2}$, sua caracterização morfométrica e os tipos de uso não favorecem a concentração do fluxo fluvial, pois seu formato é comprido e tem baixíssima tendência a ocorrência de enchentes, no entanto ressalta-se que a diminuição da cobertura vegetal é um fator de risco ao processo erosivo e consequente assoreamento dos cursos d'água.

Palavras-chave: Variáveis Fisiográficas. Geotecnologias. Planejamento Ambiental.

\section{MORPHOMETRY AND LAND USE AND COVER OF THE MOCAJUBA RIVER HYDROGRAPHIC BASIN, AMAZON COASTAL ZONE}

Abstract: The Mocajuba river hydrographic basin is located in the eastern sector of the Amazon coastal zone and its area covers four municipalities of the state Pará. This work aims to make an analysis of the morphometry and land use and cover of the basin under study. The methodology is based on the survey of geometric parameters, relief and drainage, and the classification of a Landsat 8 satellite image from the year 2019. The results show that the basin under study has an area of $329,69 \mathrm{~km}^{2}$, its morphometric characterization and the types of use do not favor the concentration of the river flow, because its shape is long and has a very low tendency to flooding, however it is emphasized that the reduction of the vegetation cover is a risk factor to the erosive process and consequent silting up of the water courses.

Keywords: Physiographic Variables. Geotechnologies. Environmental Planning.

\section{ANÁLISIS DE LA MORFOMETRÍA Y EL USO Y COBERTURA DE LA TIERRA DE LA CUENCA HIDROGRÁFICA DEL RÍO MOCAJUBA, ZONA COSTA AMAZÓNICA}

Resumen: La cuenca hidrográfica del río Mocajuba está ubicada en el sector oriental de la zona costera amazónica y su área cubre cuatro municipios en Pará. El trabajo tiene como objetivo hacer un análisis de la morfometría y el uso y la

\footnotetext{
${ }^{1}$ Universidade Federal do Pará, Instituto de Filosofia e Ciências Humanas, Belém-PA, Brasil, jonesremo@hotmail.com, https://orcid.org/0000-0001-9470-0240

2 Universidade Federal do Pará, Instituto de Filosofia e Ciências Humanas, Belém-PA, Brasil, leticiacosta.soares@gmail.com, https://orcid.org/0000-0003-3641-3029

3 Universidade Federal do Pará, Instituto de Filosofia e Ciências Humanas, Belém-PA, Brasil, mapimentel@ufpa.br, https://orcid.org/0000-0001-9893-9777
} 
cobertura de la tierra de la cuenca en estudio. La metodología se basa en el estudio de parámetros geométricos, relieve y drenaje, y la clasificación de una imagen satelital Landsat 8 del año 2019. Los resultados muestran que la cuenca tiene un área de $329,69 \mathrm{~km}^{2}$, su caracterización morfométrica y los tipos de uso no favorecen la concentración del flujo del río, ya que su forma es larga y tiene una tendencia muy baja a las inundaciones, sin embargo, se enfatiza que la reducción de la cubierta vegetal es un factor de riesgo para el proceso erosivo y el consiguiente enlodamiento del agua. cursos de agua.

Palabras clave: Variables Fisiográficas. Geotecnologías. Planificación Ambiental.

\section{INTRODUÇÃO}

A bacia hidrográfica caracteriza-se como uma área da superfície terrestre de captação natural da água das chuvas que drenam para um rio principal e seus tributários que confluem até resultar em um leito único no seu exutório, sendo limitada pelos divisores topográficos (BOTELHO, 1999). Ela é considera uma unidade ambiental integradora que permite analisar as inter-relações dos seus elementos através de uma abordagem sistêmica. Essa unidade ambiental, no caso brasileiro, constitui-se como referência espacial territorial para fins de planejamento e gestão conforme estabelecido na Política Nacional de Recursos Hídricos (PNRH), Lei Federal oㅜ 9.433/97.

Para o planejamento e gerenciamento de bacias hidrográficas é fundamental conhecer tanto as suas características físicas quanto os processos de uso e cobertura da Terra que ocorrem nos seus limites territoriais, pois a correlação entre a morfometria e os usos permite estabelecer o grau das intervenções antrópicas na unidade, ou seja, avaliar a suscetibilidade natural frente às ações externas à bacia (BARROS et al., 2016).

As intervenções antrópicas passaram a modificar as características do ambiente natural da bacia hidrográfica, com isso, vários aspectos fisiográficos do ambiente são alterados como: o relevo, o uso, a vegetação, a fauna, a hidrologia e o clima. As ações antrópicas têm acelerado e potencializado alterações nas características fisiográficas por meio da canalização e retilinização de cursos fluviais, terraplanagem e impermeabilização do solo (OLIVEIRA et al., 2011). Além disso, está cada vez mais comum à ocupação das Áreas de Preservação Permanentes (APP) pelas atividades agropastoris (FREITAS et al., 2013), sendo que essas são protegidas conforme estabelecido pela Lei Federal oㅜ 12.651/12 devido à extrema importância para o ambiente. 
A compreensão das características fisiográficas torna-se fundamental no diagnostico ambiental da bacia hidrográfica, pois o seu quadro natural pode se conformar em suscetibilidade a enchentes (VILLELA; MATTOS, 1975; VALE; BORDALO, 2020). De acordo com Tucci (2009), os dados fisiográficos podem ser extraídos de mapas, fotografias aéreas e imagens de satélite. Assim, os desenvolvimentos tecnológicos têm permitido avanços na elaboração de banco de dados ambientais.

As tecnologias espaciais modernas, também conhecidas como geotecnologias, principalmente, o Sensoriamento Remoto e o Sistema de Informação Geográfica (SIG) tem auxiliado nos estudos de bacias hidrográficas uma vez que possibilitam integração de dados dos sistemas naturais e permitem combinações e sínteses dos dados ambientais (BABU et al., 2014; MAGESH et al., 2013, 2012). Dessa forma, trabalhos como Costa et al. (2020), Silva e Girão (2020), Andrade et al. (2019), Lopes et al. (2018), Menezes e Salgado (2018), Soares et al. (2018), Ávila et al. (2017), Leal e Tonello (2016) utilizaram as geotecnologias para gerar um banco de dados ambientais para auxiliar no gerenciamento de bacias hidrográficas.

Nesta perspectiva, objetivo desse trabalho foi caracterizar a morfometria e o uso e cobertura da terra bacia hidrográfica do rio Mocajuba, para subsidiar o planejamento ambiental.

\section{ÁREA DE ESTUDO}

A bacia hidrográfica do rio Mocajuba (Figura 01) abrange o território de quatro municípios paraenses, são eles: Terra Alta (nascente do rio Mocajuba), São João da Ponta (margem esquerda do rio Mocajuba), Curuçá (margem direita do rio Mocajuba) e São Caetano de Odivelas (foz do rio Mocajuba). Na área da bacia encontram-se demarcadas três Unidades de Conservação (UCs) do tipo Reserva Extrativista (Resex). Na porção oeste a Resex Marinha de São João da Ponta e a Resex Marinha Mocapajuba, e na porção leste a Resex Marinha Mãe Grande de Curuçá. 
Figura 01 - Localização geográfica da área de estudo

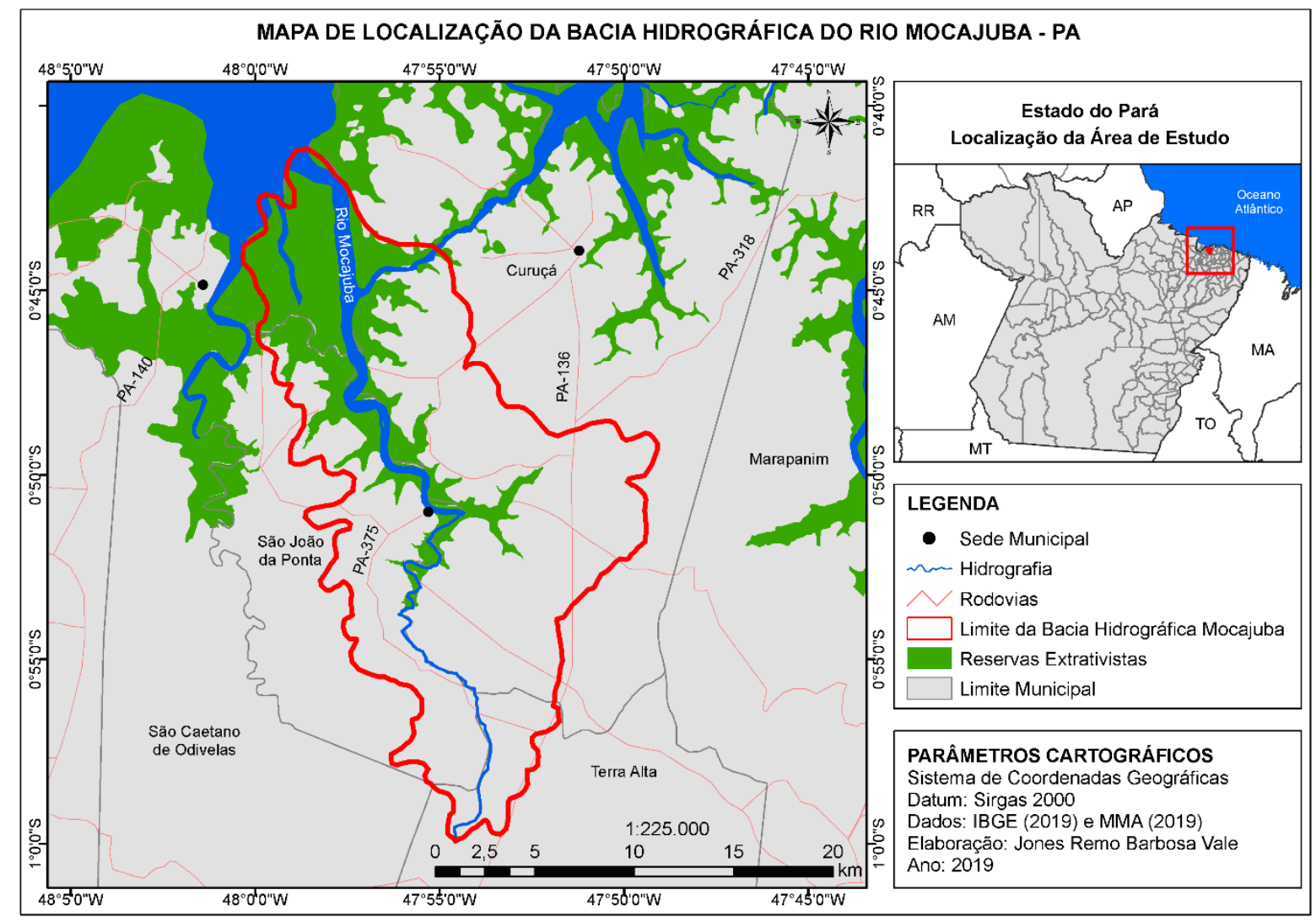

Fonte: Elaborado pelos autores (2019).

A área de estudo se encontra em um sistema estuarino no setor leste da zona costeira amazônica, a compartimentação morfológica se caracteriza por reentrâncias que definem uma configuração extremamente recortada para a sua linha de costa denominada de "litoral de rias" e apesar do rio Mocajuba ter sua foz incluída nesse sistema estuarino, ele recebe maior influência do oceano atlântico por meio de uma conexão com o rio Curuçá (PROST; MENDES, 2013).

\section{MATERIAIS E MÉTODOS}

Para o desenvolvimento do trabalho foi utilizada a base cartográfica em formato shapefile disponibilizada pelo Instituto Brasileiro de Geografia e Estatística (IBGE) e o Modelo Digital de Elevação (MDE) da missão SRTM (Shuttle Radar Topography Mission), com resolução espacial de 30m (Folha SA-22-X-B e Folha SA23-V-A) disponibilizado pela Empresa Brasileira de Pesquisa Agropecuária (Embrapa). Para a classificação do uso e cobertura da terra foi utilizada a imagem do satélite Landsat 8, sensor OLI/TIRS referente ao ano de 2019.

A delimitação de uma bacia hidrográfica é um dos primeiros e mais comuns procedimentos executados em análises hidrológicas ou ambientais (CARDOSO et 
al., 2006). Com base no método de delimitação de bacia desenvolvido por Leite e Rocha (2016) aplicou-se o procedimento metodológico de delimitação (Figura 02), para tal utilizou-se a ferramenta de extensão ArcHydro Tools.

Figura 02 - Etapas metodológicas de delimitação da bacia hidrográfica

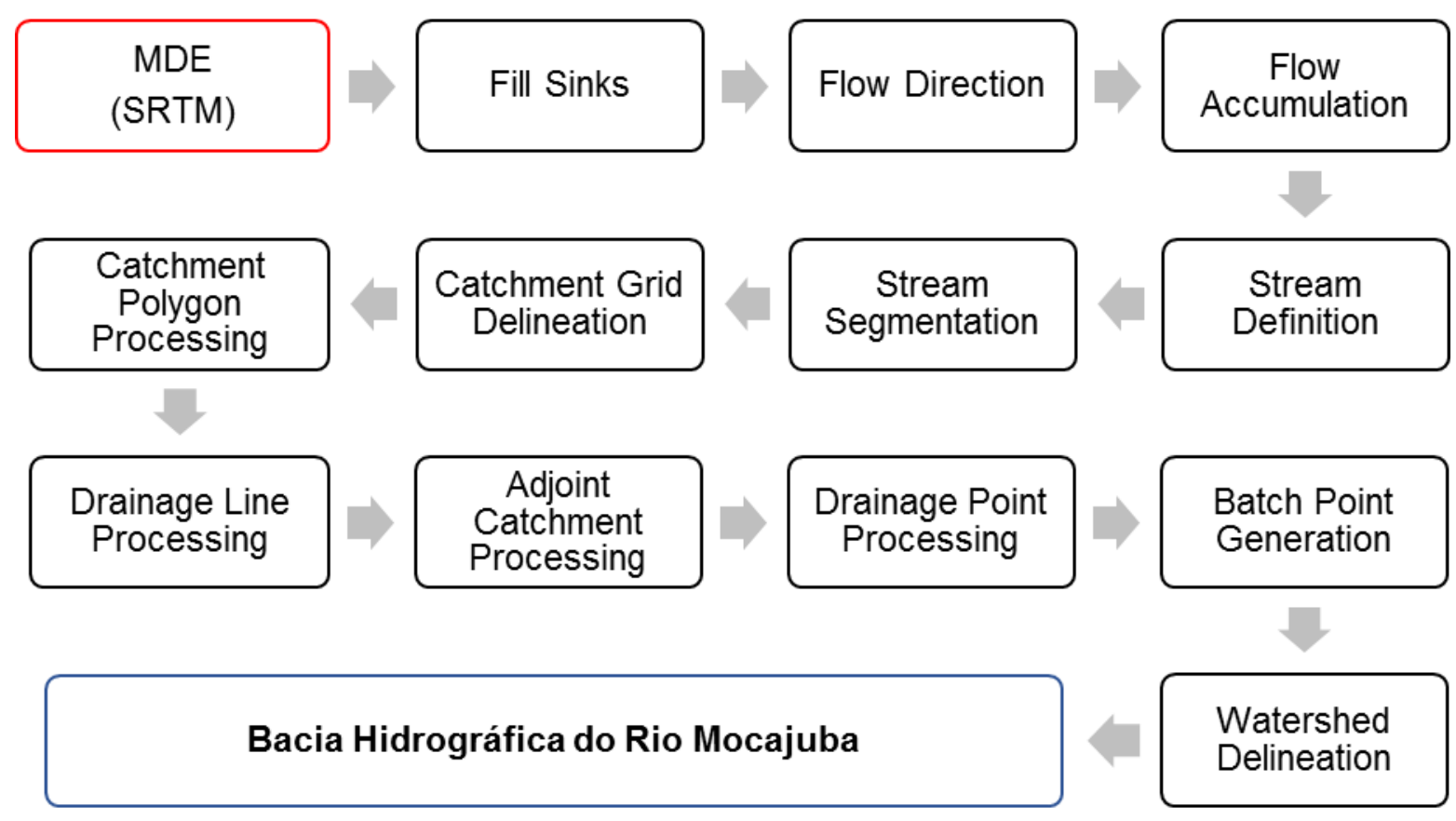

Fonte: LEITE; ROCHA (2016). Adaptado pelos autores (2019).

Após a delimitação da bacia hidrográfica do rio Mocajuba extraíram-se as informações morfométricas, cujas definições e as equações estão dispostas em: Strahler (1952), Schumm (1956), França (1968), Libault (1975), Villela e Mattos (1975), Christofoletti (1980), Piedade (1980), Tonello (2005), Cardoso et al. (2006) e Carvalho et al. (2009).

$A$ área da bacia hidrográfica $(A)$ é toda área drenada pelo sistema pluvial entre seus divisores topográficos (TONELLO, 2005). O perímetro $(P)$ consiste no comprimento da linha imaginária ao longo do divisor de águas (TONELLO, 2005). $O$ comprimento total dos cursos fluviais (Lt) refere-se à soma de todos os comprimentos dos rios que fazem parte da bacia em estudo.

A densidade de drenagem ( $D d$ ) é expressa pelo comprimento total $(L t)$ de todos os cursos d'água da bacia e a área contribuinte (A). Este índice é indicativo da maior ou menor velocidade com que a água deixa a bacia, mostra o grau de desenvolvimento do sistema de drenagem (GUARIZ, 2008). O Quadro 01 apresenta a classificação da densidade de drenagem cuja formulação é: 
$\mathrm{Dd}=\frac{\mathrm{Lt}}{\mathrm{A}}$

Quadro 01 - Valores e interpretação de densidade de drenagem

\begin{tabular}{|ccc|}
\hline Dd & Tipo & Interpretação para a bacia hidrográfica \\
\hline$<1,5$ & Baixa & Baixo escoamento superficial e maior infiltração \\
$1,5-2,5$ & Média & Tendência mediana de escoamento superficial \\
$2,5-3,0$ & Alta & Alta tendência ao escoamento superficial e enxurradas \\
$>3,0$ & Muito alta & Alta tendência ao escoamento superficial, enxurradas e erosão \\
\hline
\end{tabular}

Fonte: FRANÇA (1968). Adaptado pelos autores (2019).

O fator de forma (Kf) indica a relação da forma da bacia, correspondendo à razão entre área $(A)$ e o comprimento do curso d'água principal da bacia $(L)$. É um índice que exprime a maior ou menor tendência para enchentes. Uma bacia com um fator de forma baixo tem menos tendência para enchentes que uma bacia do mesmo tamanho, mas com um fator de forma superior (VILLELA; MATTOS, 1975). O fator de forma é dado pela seguinte equação:

$\mathrm{Kf}=\frac{\mathrm{A}}{\mathrm{L}^{2}}$

O índice de circularidade (Ic) corresponde ao coeficiente para avaliar a unidade, nele verifica-se se à medida que o valor da bacia diminui ou aumenta, possibilitando interpretar se a unidade tem a forma alongada ou não (CARDOSO et al., 2006). O índice de circularidade é dado pela seguinte expressão:

Ic $=\frac{(12,57 * A)}{\mathrm{P}^{2}}$

O coeficiente de compacidade $(\mathrm{Kc})$ constitui a relação entre o perímetro da bacia $(P)$ e a circunferência de um círculo de área igual ao da bacia (CARVALHO et al., 2009). Um coeficiente mínimo igual a uma unidade corresponderia a uma bacia circular e, para uma bacia alongada, seu valor é significativamente superior a um (VILLELA; MATTOS, 1975). O coeficiente de compacidade é dado pela seguinte expressão:

$\mathrm{Kc}=0,28 * \frac{\mathrm{P}}{\sqrt{\mathrm{A}}}$

Para os parâmetros de forma, circularidade e compacidade os resultados encontrados podem ser interpretados de acordo com o Quadro 02. 
Quadro 02 - Valores e a interpretação dos resultados quanto aos índices: fator de forma (Kf), índice de circularidade (Ic) e, coeficiente de compacidade (Kc)

\begin{tabular}{|ccclc|}
\hline Kf & lc & Kc & Formato & Interpretação para a bacia hidrográfica \\
\hline $0,75-1,0$ & $1,0-0,80$ & $1,0-1,25$ & Redonda & Alta tendência a enchentes \\
$0,50-0,75$ & $0,8-0,6$ & $1,25-1,50$ & Mediana & Média tendência a enchentes \\
$0,30-0,50$ & $0,6-0,40$ & $1,50-1,70$ & Oblonga & Baixa tendência a enchentes \\
$<0,30$ & $<0,40$ & $>1,70$ & Comprida & Tendência a conservação \\
\hline
\end{tabular}

Fonte: VILLELA; MATTOS (1975). Adaptado pelos autores (2019).

O coeficiente de manutenção dos canais $(\mathrm{Cm})$ é o inverso da densidade de drenagem. Especificamente, esse índice mostra a área de drenagem necessária em quilômetros quadrados, para sustentar um quilômetro linear de canal (SCHUMM, 1956). O coeficiente de manutenção dos canais é dado pela seguinte expressão:

$\mathrm{Cm}=\frac{1}{\mathrm{Dd}} * 100$

A hierarquia fluvial é um processo que consiste em estabelecer a classificação de determinado curso d'água no conjunto da bacia hidrográfica a qual pertence. De acordo com Strahler (1952), os menores canais, sem tributários, são considerados de primeira ordem, os canais de segunda ordem surgem da confluência dos canais de primeira ordem e só podem receber afluentes de primeira ordem, os canais de terceira ordem surgem da confluência de dois canais de segunda ordem, podendo receber afluentes de primeira e de segunda ordem e assim sucessivamente.

O Índice de Sinuosidade se refere à razão entre o comprimento do curso d'água principal da bacia (L) e seu comprimento vetorial (Dv) que é a distância em linha reta entre as extremidades do curso principal. Este parâmetro se constitui como um fator controlador da velocidade de escoamento das águas (SALGADO et al., 2009), obtido pela seguinte expressão:

IS $=\frac{\mathrm{L}}{\mathrm{Dv}}$

A relação de bifurcação $(\mathrm{Rb})$ é a relação entre o número total de segmentos de certa ordem $(\mathrm{Nu})$ e o número total dos de ordem imediatamente superior $(\mathrm{Nu}+1)$ (CHRISTOFOLETTI, 1980). Os valores de bifurcação indicam o grau de dissecação da bacia e, quanto maior for o valor do índice maior será o grau de dissecação 
(CASTRO; CARVALHO, 2009). O coeficiente da relação de bifurcação é dado pela seguinte expressão:

$\mathrm{Rb}=\frac{\mathrm{Nu}}{\mathrm{Nu}+1}$

A razão de textura $(\mathrm{T})$ é a relação do número total de rios $(\mathrm{Nt})$ e o perímetro da bacia $(\mathrm{P})$, onde à medida que o relevo passa de suave ondulado para ondulado, os valores médios da razão de textura aumentam refletindo num mesmo ambiente climático, condição em que a infiltração da água encontra maior dificuldade (NARDINI et al., 2015). A classificação da razão de textura está no Quadro 03 e 0 cálculo é expresso por:

$\mathrm{T}=\frac{\mathrm{Nt}}{\mathrm{P}}$

A razão de relevo $(\mathrm{Rr})$ é a relação entre a maior altitude em metros $(\mathrm{H})$ e 0 maior comprimento em metros (C), que corresponde à direção do vale principal, entre a foz e o ponto extremo sobre a linha do divisor de águas (SCHUMM, 1956). A razão do relevo é dada pela seguinte expressão:

$\operatorname{Rr}=\frac{\mathrm{H}}{\mathrm{C}}$

Quadro 03 - Classificação da razão de textura

\begin{tabular}{|cc|}
\hline VALOR & CLASSIFICAÇÃO \\
\hline$<2,5$ & Grosseira \\
$2,5-6,2$ & Média \\
$>6,2$ & Fina \\
\hline
\end{tabular}

Fonte: FRANÇA (1968). Adaptado pelos autores (2019).

O parâmetro razão de relevo permite comparar a altimetria da área, demonstrando que, quanto maiores os valores, mais acidentado é o relevo predominante na área, maior será o escoamento superficial direto da água das chuvas, o que reflete numa menor relação infiltração deflúvio, provocando erosão (NARDINI et al., 2015). A razão do relevo pode ser classificada conforme Quadro 04. 
Quadro 04 - Classificação da razão do relevo

\begin{tabular}{|cc|}
\hline VALOR & CLASSIFICAÇÃO \\
\hline 0 a 0,10 & Baixa \\
0,11 a 0,30 & Média \\
0,31 a 0,60 & Alta \\
\hline
\end{tabular}

Fonte: PIEDADE (1980). Adaptado pelos autores (2019).

A declividade representa a variável do desnível, isto é, a diferença de altitude entre o ponto mais alto e o mais baixo de uma área (LIBAULT, 1975). Quanto maior o ângulo da declividade, mais rapidamente a energia potencial das águas pluviais se transformam em energia cinética, aumentando a velocidade das massas d'água e sua capacidade de transporte (SILVEIRA et al., 2005). Segundo Florenzano (2008), a declividade pode ser expressa em graus ou em porcentagem. A Embrapa (1979) sugere a classificação do relevo como: 0 a 3\% plano; de 3 a $8 \%$ suave ondulado; de 8 a $20 \%$ ondulado; de 20 a $45 \%$ forte ondulado e de 45 a $75 \%$ montanhoso.

A altitude influencia na quantidade de radiação que recebida $e$, consequentemente, a evapotranspiração, temperatura e precipitação. A relação da altitude com o balanço de energia se dá em função das variações na altitude que ocasionam diferenças significativas na temperatura, que, por sua vez, também causa variações na evapotranspiração (GUARIZ, 2008). A altitude média (Hm) é dada pela relação entre a altitude máxima (MA) e a altitude mínima (mA), expressa por:

$\mathrm{Hm}=\frac{\mathrm{MA}+\mathrm{mA}}{2}$

A amplitude altimétrica $(\Delta \mathrm{H})$ é dada pela diferença entre maior cota $(\mathrm{MA})$ e a menor $(\mathrm{mA})$ da bacia:

$\Delta \mathrm{H}=\mathrm{MA}-\mathrm{mA}$

O índice de rugosidade (Ir) é produto da amplitude altimétrica $(\Delta H)$ pela densidade de drenagem (Dd). Os valores baixos ou elevados do índice ocorrem somente quando ambos os fatores apresentarem mesmo comportamento (CHRISTOFOLETTI, 1980). O índice de rugosidade é dado pela seguinte expressão: 
A hipsometria (Quadro 05) refere-se à distribuição espacial das altitudes, que pode também ser correlacionado a índices morfométricos, como a amplitude altimétrica e o índice de rugosidade. Os dados hipsométricos possibilitam obter 0 conhecimento do relevo quanto ao potencial erosivo (CALIL, 2009).

Quadro 05 - Classificação da hipsometria

\begin{tabular}{|cc|}
\hline VALOR & CLASSIFICAÇÃO \\
\hline $0-20 \mathrm{~m}$ & Planícies \\
$20-50 \mathrm{~m}$ & Colinas suaves \\
$50-100 \mathrm{~m}$ & Colinas \\
\hline
\end{tabular}

Fonte: MENEZES; SALGADO (2018). Adaptado pelos autores (2019).

A classificação do uso e cobertura da terra foi realizada no Google Earth Engine (GEE), esta é uma geotecnologia em forma de plataforma online que integra um conjunto de dados geoespaciais em escala planetária com capacidade de armazenamento e processamento altamente elevados (GORELICK et al., 2017). Para realizar a classificação desenvolveu-se um script na linguagem JavaScript, com aplicação do algoritmo Random Forest, que segundo Breiman (2001) é um classificador formado por uma coleção de árvores de classificação. As características das classes mapeadas estão dispostas no Quadro 06.

Quadro 06 - Características das classes de uso e cobertura da Terra

\begin{tabular}{|c|c|}
\hline CLASSE & \multicolumn{1}{c|}{ CARACTERÍSTICAS } \\
\hline Cobertura Vegetal & $\begin{array}{l}\text { Área de floresta primária, com vegetação arbórea pouco alterada ou } \\
\text { sem alteração, com formação de dossel contínuo. Áreas que, após a } \\
\text { supressão total da vegetação florestal, encontra-se em processo de } \\
\text { regeneração. }\end{array}$ \\
Hidrografia & Águas superficiais formadoras de espelhos d'água. \\
Mosaico Agricultura e e & $\begin{array}{l}\text { Áreas que, após o corte raso da vegetação natural desenvolvem a } \\
\text { Pastagem }\end{array}$ \\
atividade agropastoril, com cultivos agrícolas e vegetação herbácea \\
e/ouneas.
\end{tabular}


Fonte: Elaborado pelos autores (2019).

A avaliação da classificação foi realizada pelas seguintes etapas: distribuição aleatória de 100 pontos aleatórios nas imagens de satélite em composição colorida e verificação da exatidão por meio da matriz de confusão para cálculo do Índice Kappa, este que é uma medida de concordância que fornece uma ideia do quanto às observações se afastam daquelas esperadas, fruto do acaso, indicando-nos assim o quão legítimo são as interpretações (COHEN, 1960). O Índice Kappa é expresso por:

$\mathrm{K}=\frac{P_{0}-P_{c}}{1-P_{c}}$

Em que: $P 0$ é a exatidão global; $P c$ é a proporção de unidades que concordam por casualidade.

A partir dos resultados, Landis e Koch (1977) associam valores do Índice Kappa à qualidade da classificação de acordo com o Quadro 07.

Quadro 07 - Qualidade da classificação associada aos valores do Índice Kappa

\begin{tabular}{|cc|}
\hline Parâmetro & Qualidade da classificação \\
\hline 0,00 & Péssima \\
0,01 a 0,20 & Ruim \\
0,21 a 0,40 & Razoável \\
0,41 a 0,60 & Boa \\
0,61 a 0,80 & Muito Boa \\
0,81 a 1,00 & Excelente \\
\hline
\end{tabular}

Fonte: LANDIS; KOCH (1977). Adaptado pelos autores (2019).

Após todos os processamentos, os resultados foram analisados e apresentados em forma de tabelas e mapas confeccionados em SIG.

\section{RESULTADOS E DISCUSSÕES}

A partir do processamento dos dados foi possível obter as características morfométricos da bacia hidrográfica do rio Mocajuba que estão sintetizadas na Tabela 01, estes parâmetros foram encontrados através de dados geométricos, de relevo e drenagem. 
A bacia hidrográfica em estudo apresenta uma área de $329,69 \mathrm{~km}^{2}$, um perímetro de $113,83 \mathrm{~km}$, comprimento total dos cursos d'água de $265,59 \mathrm{~km}$, sendo o curso d'água principal com comprimento de $48,46 \mathrm{~km}$. A densidade de drenagem da bacia que é um fator importante na indicação do grau de desenvolvimento do sistema de drenagem de uma bacia foi de $0,80 \mathrm{~km} / \mathrm{km}^{2}$, ou seja, tem baixo escoamento superficial e maior infiltração e o padrão de drenagem da bacia é dendrítico.

Tabela 01 - Parâmetros morfométricos da bacia hidrográfica do rio Mocajuba

\begin{tabular}{|c|c|}
\hline PARÂMETRO & RESULTADOS \\
\hline \multicolumn{2}{|c|}{ Características Geométricas } \\
\hline Área & 329,69 km² \\
\hline Perímetro & $113,83 \mathrm{~km}$ \\
\hline Fator forma & 0,14 \\
\hline Coeficiente de compacidade & 1,75 \\
\hline Índice de circularidade & 0,31 \\
\hline Padrão de drenagem & Dendrítico \\
\hline \multicolumn{2}{|c|}{ Características do Relevo } \\
\hline Altitude média & $29,5 \mathrm{~m}$ \\
\hline Altitude mínima & $1 \mathrm{~m}$ \\
\hline Altitude máxima & $59 \mathrm{~m}$ \\
\hline Amplitude altimétrica & $58 \mathrm{~m}$ \\
\hline Razão de textura & 1,19 \\
\hline Razão de relevo & 0,001 \\
\hline Índice de rugosidade & 46,40 \\
\hline \multicolumn{2}{|c|}{ Características da Drenagem } \\
\hline Ordem da bacia hidrográfica & $4^{\circ}$ \\
\hline Número total de canais & 136 \\
\hline Densidade de drenagem & $0,80 \mathrm{~km} / \mathrm{km}^{2}$ \\
\hline Índice de Sinuosidade & 1,37 \\
\hline Coeficiente de manutenção dos canais & $1,25 \mathrm{~km}^{2}$ \\
\hline Comprimento do curso d'água principal & $48,46 \mathrm{~km}$ \\
\hline Comprimento total dos cursos d'água & $265,59 \mathrm{~km}$ \\
\hline
\end{tabular}


Fonte: Elaborado pelos autores (2019).

A bacia hidrográfica do rio Mocajuba tem um fator de forma de 0,14 , seu índice de circularidade é de 0,31 e coeficiente de compacidade de 1,75. Os resultados mostraram que a bacia, de modo geral, não favorece a concentração do fluxo fluvial, seu formato é comprido e tem baixíssima tendência a ocorrência de enchentes. O coeficiente de manutenção dos canais demonstrou que é preciso 1,25 $\mathrm{km}^{2}$ de área para manter ativo um quilômetro de canal fluvial.

Com relação ao ordenamento dos canais, tendo como referência a classificação hierárquica de Strahler (1952), a Figura 03 apresenta a hipsometria e hierarquia dos canais fluviais da bacia de estudo, sendo que a quantificação e a relação de bifurcação dos canais de acordo com sua ordem podem ser observadas nas Tabelas 02 e 03.

Figura 03 - Hipsometria e hierarquia fluvial dos cursos d'água da área de estudo

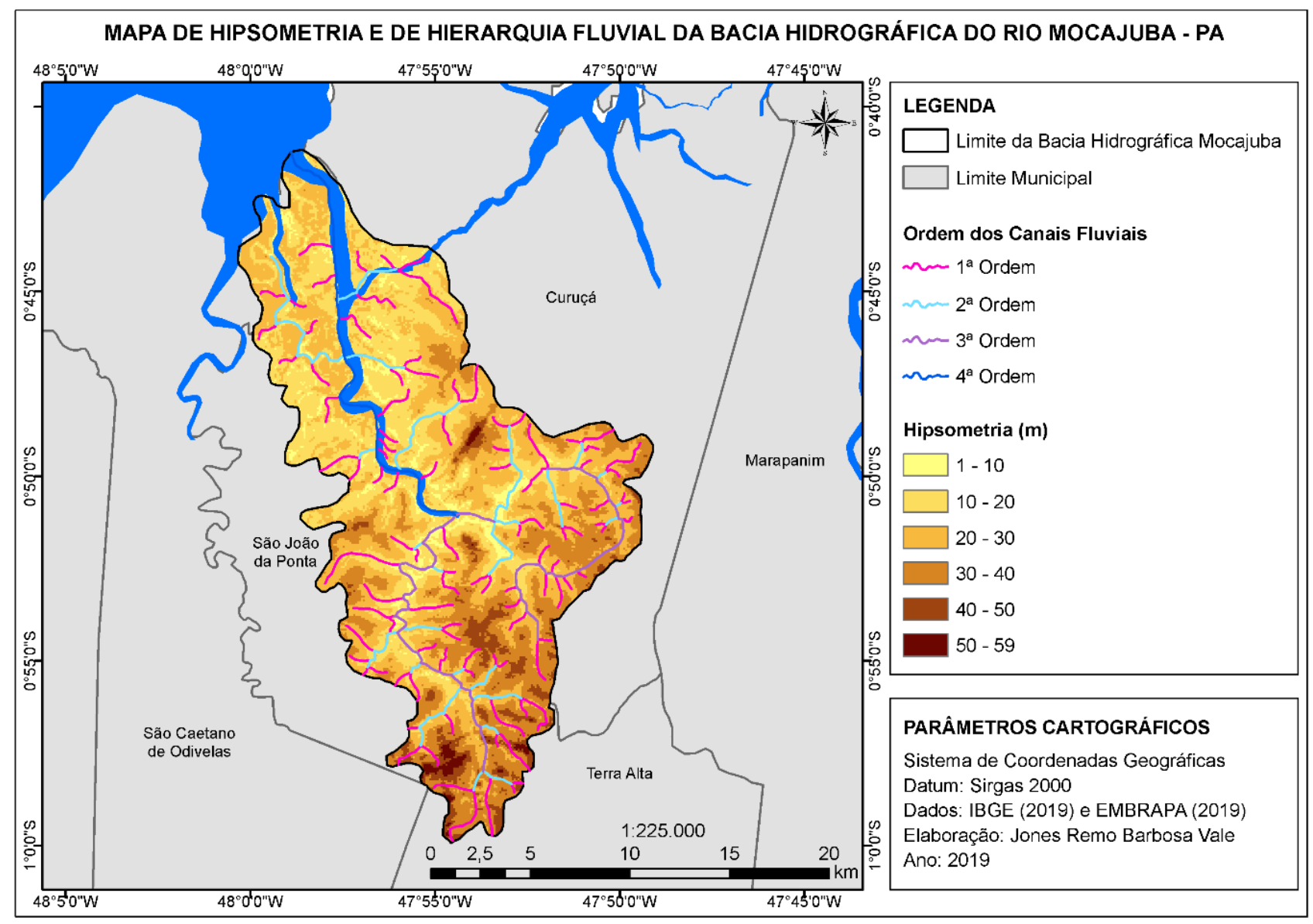

Fonte: Elaborado pelos autores (2019). 
Tabela 02 - Quantificação dos canais fluviais da bacia hidrográfica do rio Mocajuba

\begin{tabular}{ccc}
\hline ORDEM DO CANAL & QUANTIDADE & EXTENSÃO (km) \\
\hline $1^{\underline{a}}$ & 104 & 142,66 \\
$2^{\underline{a}}$ & 27 & 60,49 \\
$3^{a}$ & 4 & 38,59 \\
$4^{\underline{a}}$ & 1 & 23,85 \\
\hline TOTAL $^{a}$ & 136 & 265,59 \\
\hline
\end{tabular}

Fonte: Elaborado pelos autores (2019).

Tabela 03 - Relação de bifurcação entre os canais fluviais da bacia em estudo

\begin{tabular}{|c|c|}
\hline RELAÇÃO DE BIFURCAÇÃO & VALOR \\
\hline $1 \stackrel{\circ}{2} 2^{\circ}$ & 3,71 \\
\hline $2^{\circ} / 3^{\circ}$ & 5,4 \\
\hline $3 \div / 4^{\circ}$ & 2 \\
\hline
\end{tabular}

Fonte: Elaborado pelos autores (2019).

O índice de sinuosidade da área em estudo foi de 1,37 demonstrando uma tendência de canais retilíneos, pois valores próximos a 1,0 indicam que o canal tende a ser retilíneo. A relação de bifurcação da bacia em estudo indicou valor médio de 3,70 que segundo Horton (1945) é um valor relativamente baixo e demonstra que a bacia tem relevos aplainados.

A razão de textura foi classificada conforme os parâmetros de França (1968) como grosseira, pois o valor encontrado foi de 1,19. A razão de relevo que permite comparar a altimetria da área de estudo obteve o resultado de 0,001 sendo considerada de baixa razão.

A Figura 04 apresenta a variação da declividade da bacia, esta que influência a relação entre a precipitação e o deflúvio da bacia hidrográfica, sobretudo, devido à diminuição da velocidade de escoamento superficial, aumento da possibilidade de infiltração de água no solo. Os resultados demonstram que a bacia apresenta um relevo relativamente plano. 
Figura 04 - Declividade da área de estudo

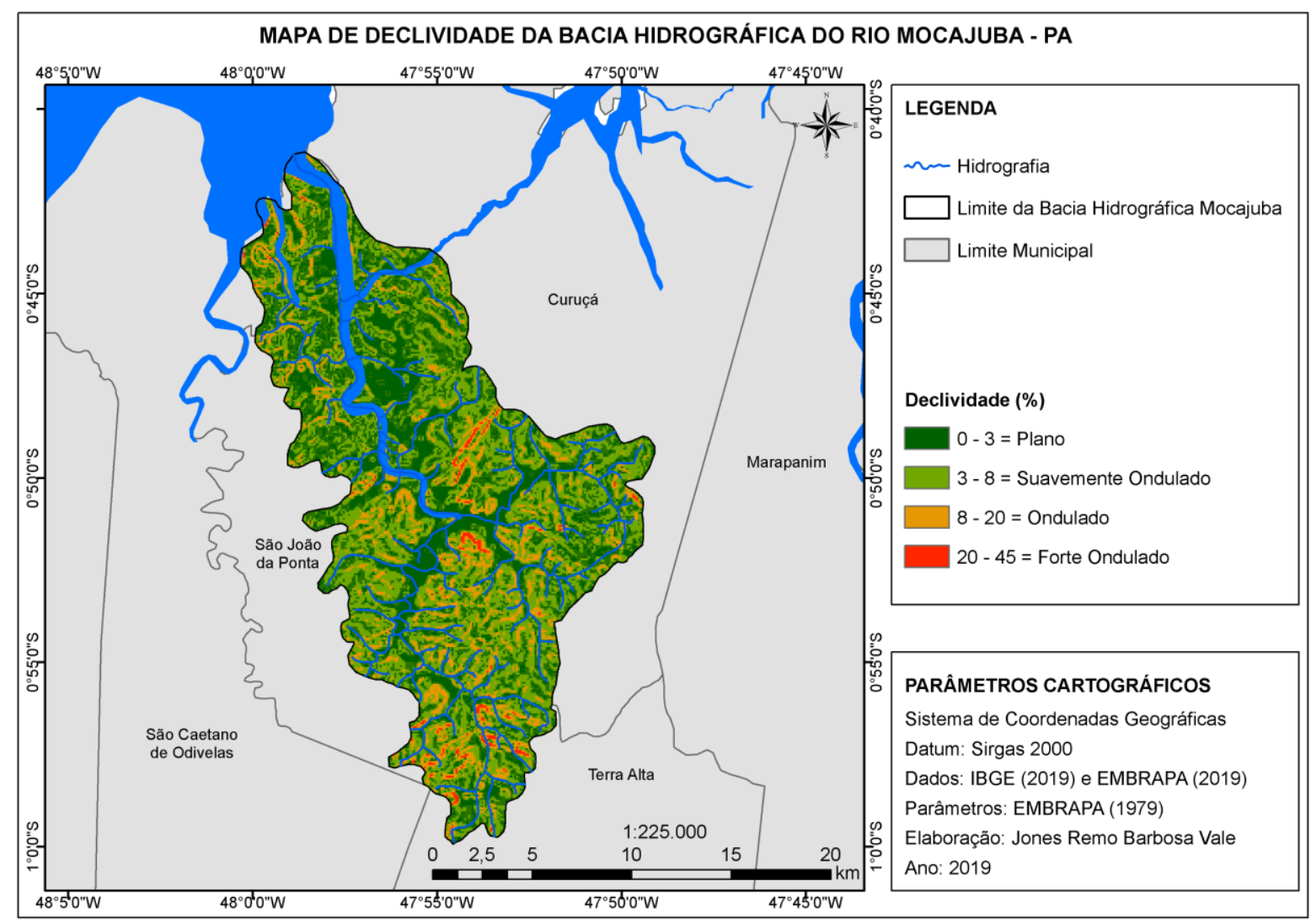

Fonte: Elaborado pelos autores (2019).

A partir do mapeamento do uso e cobertura da Terra na área da bacia constatou-se que a cobertura vegetal é a classe predominante com uma ocupação de uma área de aproximadamente $58 \%$, o que pode ser explicado pela bacia conter três UCs. A agricultura e as áreas de pastagem correspondem a aproximadamente $18 \%$ da área da bacia. A distribuição espacial de cada classe de uso e cobertura pode ser observada na Figura 05 e os valores obtidos na Tabela 04. Cabe destacar que a validação desta classificação foi realizada pelo Índice Kappa que obteve resultado de 0,77 sendo considerada muito boa. 
Figura 05 - Classificação de uso e cobertura da terra na área de estudo

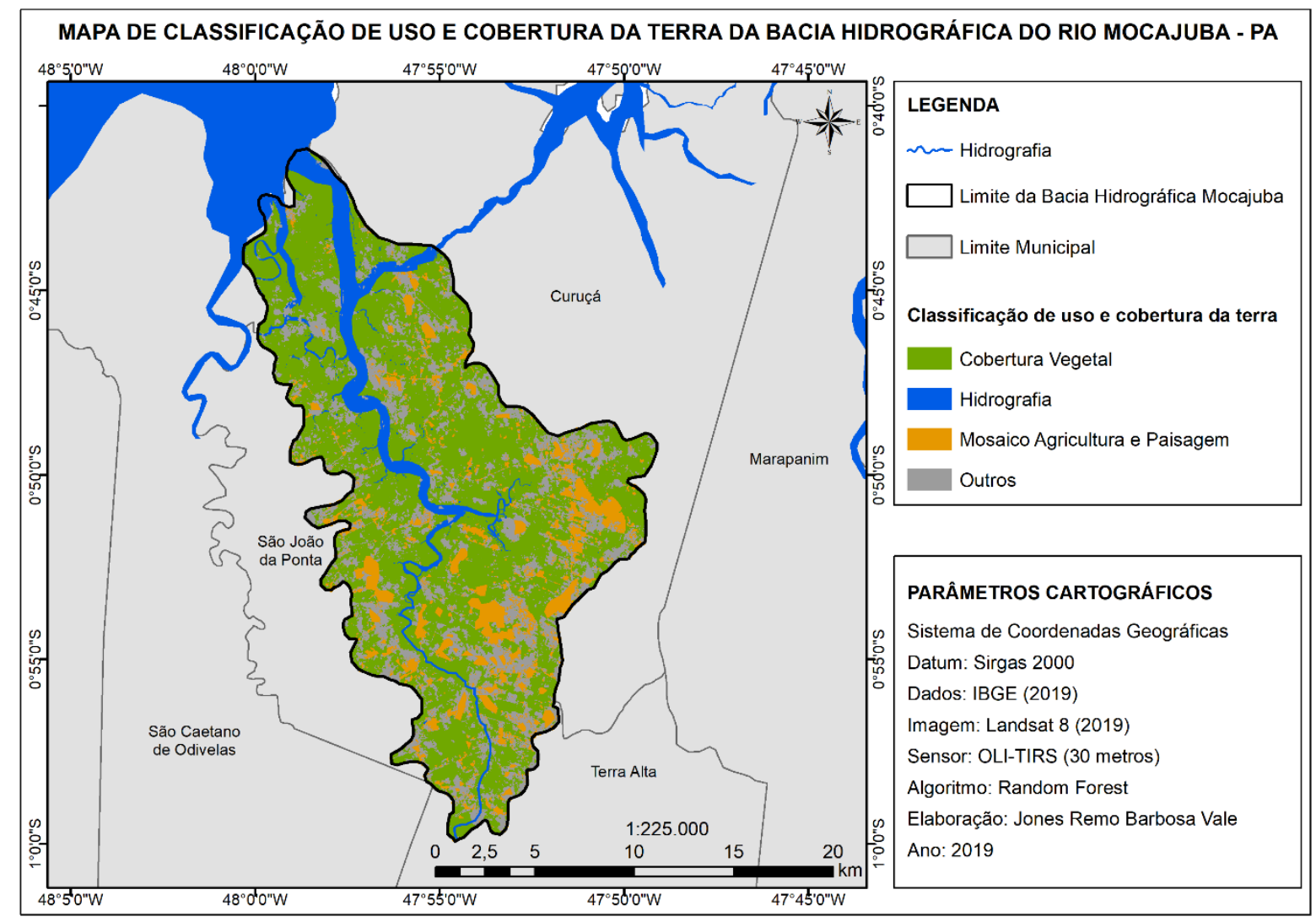

Fonte: Elaborado pelos autores (2019).

Tabela 04 - Área das classes de uso e cobertura da Terra da área de estudo

\begin{tabular}{ccc}
\hline CLASSE & ÁREA $\left(\mathbf{k m}^{2}\right)$ & ÁREA $(\%)$ \\
\hline Cobertura Vegetal & 192,41 & 58,36 \\
Hidrografia & 27,40 & 8,31 \\
Mosaico Agricultura e Pastagem & 61,57 & 18,68 \\
Outros & 48,31 & 14,65 \\
\hline TOTAL & 329,69 & 100,0 \\
\hline
\end{tabular}

Fonte: Elaborado pelos autores (2019).

$\mathrm{Na}$ área da bacia são desenvolvidos alguns cultivos agrícolas, caracterizado por cultivos temporários e permanentes, destinados à subsistência e venda no comércio local. Entre os principais cultivos destacam-se a mandioca, milho, feijão, hortaliças e frutas. Já entre o cultivo de lavouras permanentes destacam-se frutas e pimenta-do-reino. A atividade agrícola ocupa uma área de $61,57 \mathrm{~km}^{2}$, o que mostra que as áreas agrícolas são uma das atividades antrópicas responsáveis pela retirada da cobertura vegetal da área de estudo. 
O extrativismo animal com a prática da pesca de peixes, ostras, camarão, siri e caranguejo é considerado uma das principais atividades de uso realizada na bacia hidrográfica do rio Mocajuba. As populações que vivem nas comunidades as margens do rio principal e de seus afluentes, desenvolvem esse tipo de atividade, principalmente, para garantir fonte de renda, além de aquisição proteica, assim como para o lazer e sociabilidade entre os membros das comunidades. Ressalta-se que o uso desses recursos naturais ocorre de forma consciente pelas comunidades, fruto das ações de conscientização do uso racional dos recursos naturais feito pelas Associações e pelos órgãos gestores.

As condições naturais da bacia hidrográfica do rio Mocajuba demonstram que há uma tendência a conservação, pois o seu relevo é relativamente plano, tem baixo escoamento superficial e alto teor de infiltração de água no solo, o formato geométrico da bacia é comprido e tem baixa tendência a ocorrência de enchentes, porém, a supressão da cobertura vegetal e o desenvolvimento de atividades agropastoris podem agravar seu potencial erosivo e a degradação dos recursos hídricos.

Os parâmetros morfométricas apresentam atributos relacionados aos perfis ou ao traçado dos cursos d'água, permitem identificar e registrar o quão susceptível a bacia é a ocorrência de eventos de inundação, esses dados são essenciais a fim de contribuir para o planejamento e ações ambientais, onde os usos podem ser direcionados de modo que sejam compatíveis com sua aptidão e características naturais da bacia.

\section{CONSIDERAÇÕES FINAIS}

Os parâmetros fisiográficos mensurados e os usos da terra mapeados evidenciaram que a bacia em estudo tem condições naturais há uma conservação. No entanto, as ações antrópicas principalmente com o desenvolvimento de atividades agropastoris podem desencadear problemas ambientais. Assim, faz-se necessário a elaboração de medidas efetivas de recuperação e preservação de sua cobertura vegetal para enfrentamento de problemas, como por exemplo, a erosão e o assoreamento, principalmente nas áreas de preservação permanente a fim de manter a vida dos cursos d'água.

É preciso que se faça monitoramento do desenvolvimento das atividades agropastoris e de outras ações antrópicas, a fim de se verificar o quão a cobertura vegetal é suprimida. Ressalta-se que assim como a geotecnologia mostraram-se 
boas ferramentas no desenvolvimento deste trabalho, também, pode ser utilizado pelos órgãos competentes para a elaboração políticas de fiscalização e gestão recursos hídricos e ambientais para a conservação da bacia hidrográfica, pois são ferramentas que fornecem dados confiáveis e a baixo custo.

\section{REFERÊNCIAS}

ANDRADE, L. R.; MOREIRA, J. P. P. C.; SANTOS, A. M. Análise Temporal do Uso e Cobertura da Terra na Bacia do Rio Boa Vista, Ouro Preto do Oeste-RO. Caderno de Geografia, v.29, n.56, p. 81-97, 2019.

ÁVILA, B. T.; ALMEIDA NETO, J. O.; FELIPPE, M. F. Suscetibilidade morfométrica a inundações nas bacias hidrográficas tributárias do Rio do Peixe, Zona da Mata de Minas Gerais. Revista Formação, v. 01, n. 24, p. 153-181, 2017.

BABU, K. J.; SREEKUMAR, S.; ASLAM, A. Implication of drainage basin parameters of a tropical river basin of South India. Applied Water Science, v. 06, n. 67, p. 67-75, 2016.

BARROS, D. V.; SILVA, Q. D.; TEIXEIRA, E. C.; COSTA, C. M.; SANTANA, R. G. Morfometria, uso e cobertura do solo como indicadores de enchentes e inundações na Bacia do Rio do Prata, Ilha do Maranhão. Revista Brasileira de Gestão Ambiental e Sustentabilidade, v. 03, n. 05, p. 217-226, 2016.

BOTELHO, R. G. M. Planejamento ambiental em microbacias hidrográficas. In: GUERRA, A. J. T.; SILVA, A. A.; BOTELHO, R. G. M. (Org.) Erosão e Conservação dos Solos. Rio de Janeiro: Bertrand Brasil, 1999.

BRASIL. Casa Civil. Lei № 9.433, de 8 de janeiro de 1997. Institui a Política Nacional de Recursos Hídricos, cria o Sistema Nacional de Gerenciamento de Recursos Hídricos. Brasília, 1997.

BRASIL. Casa Civil. Lei № 12.651, de 25 de maio de 2012. Dispõe sobre a proteção da vegetação nativa. Brasília, 2012.

BREIMAN, L. Random Forests. Machine Learning, v. 45, p. 05-32, 2001.

CALIL, P. M. Potencial de uso por atributos morfométricos dos solos da bacia hidrográfica do Alto Rio Meia Ponte, Goiás. 2009. Dissertação (Mestrado em Agronomia) - Departamento de Ciências Agrárias, Universidade Federal de Goiás, Goiânia/GO, 2009.

CARDOSO, C. A.; DIAS, H. C. T.; SOARES, C. P. B.; MARTINS, S. V. Caracterização morfométrica da bacia hidrográfica do rio Debossan, Nova Friburgo-RJ. Revista Árvore, v. 30, n. 02, p. 241-248, 2006.

CARVALHO, W. M.; VIEIRA, E. O.; ROCHA, J. M. J.; PEREIRA, A. K. dos S.; CARMO, T. V. B. Caracterização fisiográfica da bacia hidrográfica do Córrego do Malheiro, no município de Sabará - MG. Revista Irriga, v. 14, n. 03, p. 398-412, 2009.

CASTRO, S. B.; CARVALHO, T. M. Análise morfométrica e geomorfologia da bacia hidrográfica do rio Turvo - GO, através de técnicas de sensoriamento remoto e geoprocessamento. Scientia Plena, v. 05, n. 02, p. 01-07, 2009.

CHRISTOFOLETTI, A. Geomorfologia. São Paulo: Edgard Blücher, 1980. 
COHEN, J. A. Coefficient of Agreement for Nominal Scales. Educational and Psychological Measurement, v. 20, n. 01, p. 37-46, 1960.

COSTA, A. A. D.; GALVANIN, E. A. dos S.; NEVES, S. M. A. da S. Análise morfométrica da bacia hidrográfica Paraguai/Jauquara, Mato Grosso - Brasil. Geosul, v. 35, n. 74, p. 483500, 2020.

EMBRAPA. Empresa Brasileira de Pesquisa Agropecuária. Serviço Nacional de Levantamento e Conservação de Solos (Rio de Janeiro, RJ). In: Súmula da X Reunião Técnica de Levantamento de Solos, Rio de Janeiro, 1979.

FLORENZANO, T. G. Geomorfologia: conceitos e tecnologias atuais. São Paulo: Oficina de Textos, 2008.

FRANÇA, G. V. Interpretação fotográfica de bacias e redes de drenagem aplicada a solos da região de Piracicaba. 1968. Tese (Doutorado em Agronomia/Solos e Nutrição de Plantas) - Escola Superior de Agricultura "Luiz de Queiroz", Universidade de São Paulo, Piracicaba/SP.

FREITAS, E. P.; MORAES, J. F. L.; PECHE FILHO, A.; STORINO, M. Indicadores ambientais para áreas de preservação permanente. Revista Brasileira de Engenharia Agrícola e Ambiental, v. 17, n. 04, p. 443-449, 2013.

GORELICK, N; HANCHER, M.; DIXON, M.; ILYUSHCHENKO, S; THAU, D.; MOORE, R. Google Earth Engine: Planetary-scale geospatial analysis for everyone. Remote Sensing of Environment, v. 202, p. 18-27, 2017.

\section{GUARIZ, H. R. Morfometria e atributos físicos do solo da microbacia do Córrego} Jaqueira-Alegre, ES. 2008. Dissertação (Mestrado em Produção Vegetal) - Departamento de Ciências Agrárias, Universidade Federal do Espírito Santo, Alegre/ES, 2008.

HORTON, R. E. Erosional development of streams and their drainage basins: Hydrographical approach to quantitative morphology. Bulletin of the Geological Society of America, v.56, n. 02, p. 275-370, 1945.

LANDIS, J. R.; KOCH, G. G. The measurement of observer agreement for categorical data. Biometrics, v. 33, n. 01, p. 159-174, 1977.

LEAL, M. S.; TONELLO, K. C. Análise da morfometria e do uso e cobertura da terra da microbacia do córrego Ipaneminha de Baixo, Sorocaba/SP. Floresta, v. 46, n. 4, p. 439-446, 2016.

LEITE, M. E.; ROCHA, A. M. Sistema de Informações Geográficas (SIG) aplicado ao cálculo de índices morfométricos em bacia hidrográfica. Geo UERJ, n. 28, p.44-65, 2016.

LIBAULT, A. Geocartografia. São Paulo: Companhia Editora Nacional/USP, 1975. LOPES, E. R. N.; SOUZA J. C.; SOUSA J. A. P.; ALBUQUERQUE FILHO, J. L.; LOURENÇO, R. W. Modelagem ambiental de bacias hidrográficas: caracterização morfométrica e pedológica da bacia do Rio Una - Ibiúna, Brasil. Geosul, v. 33, n. 66, p.105$127,2018$.

MAGESH N. S; CHANDRASEKAR, N.; KALIRAJ, S. A GIS based automated extraction tool for the analysis of basin morphometry. Bonfring International Journal of Industrial

Engineering and Management Science, v. 02, n. 01, p. 32-35, 2012. 
MAGESH, N. S.; JITHESHLAL, K. V.; CHANDRASEKAR, N.; JINI, K. V. Geographical information system-based morphometric analysis of Bharathapuzha river basin, Kerala, India. Applied Water Science, v. 03, p. 467-477, 2013.

MENEZES, C. R.; SALGADO, C. M. caracterização morfométrica e de intervenções urbanas na bacia hidrográfica do rio Imboaçu (São Gonçalo, RJ): contribuição ao estudo de inundações. Revista Formação, v. 25, n. 44, p. 279-299, 2018.

NARDINI, R. C.; GOMES, L. N.; CAMPOS, S.; SILVEIRA, G. R. Análise da caracterização morfométrica da microbacia do Ribeirão dos Patos, Bofete (SP). Geografia, Londrina, v. 24. n. 2, p. 25-39, 2015.

OLIVEIRA, E. D.; OLIVEIRA, E. D.; CRESTANI, A.; ALMEIDA, N. A. Caracterização fisiográfica da bacia de drenagem do Córrego Jandaia, Jandaia do Sul/PR. ACTA Geográfica, v. 05, n.10, p.169-183, 2011.

PIEDADE, G. C. R. Evolução de voçorocas em bacias hidrográficas do município de Botucatu, SP. 1980. Tese (Livre Docência) - Faculdade de Ciências Agronômicas/UNESP, Botucatu/SP, 1980.

PROST, M. T.; MENDES, A. C. Ecossistemas Costeiros: impactos e gestão ambiental. 2. Ed. Belém: Museu Paraense Emílio Goeldi, 2013.

SALGADO, M. P. G.; BATISTA, G. T.; DIAS, N. W.; TARGA, M. dos S. Caracterização de uma microbacia por meio de geotecnologias. In: SIMPÓSIO BRASILEIRO DE SENSORIAMENTO REMOTO, 14., 2009, Natal/RN. Anais [...] São José dos Campos: INPE, 2009. p. 4837-4843.

SCHUMM, S. A. Evolution of drainage systems and slopes in badlands at Perth Ambory, New Jersey. Bulletin of the Geological Society of America, n. 67, p.597-646, 1956.

SILVA, C. S. da; GIRÃO, O. Análise morfométrica e caracterização geomorfológica da Bacia Hidrográfica do Rio Jaboatão (BHRJ) - Pernambuco. Geosul, v. 35, n. 75, p. 441-460, 2020.

SILVEIRA, C. T. da.; FIORI, A. P.; FIORI, C. O. Estudo das unidades ecodinâmicas de instabilidade potencial na Apa de Guaratuba: subsídios para o planejamento ambiental. Boletim Paranaense de Geociências, n. 57, p. 09-23, 2005.

SOARES, M. R. G. DE J.; FIORI, C. O.; SILVEIRA, C. T.; KAVISKI, E. Avaliação do método de levantamento morfométrico em bacias hidrográficas através da estatística multivariada.

Geosul, v. 33, n. 68, p. 83-97, 2018.

STRAHLER, A. N. Dynamic basis of geomorphology. Bulletin of the Geological Society of America, v. 63, p. 923-938, 1952.

TONELLO, K. C. Análise hidroambiental da bacia hidrográfica da cachoeira das

Pombas, Guanhães, MG. 2005. Tese (Doutorado em Ciências Florestal) - Universidade Federal de Viçosa, Viçosa, 2005.

TUCCI, C. E. M. (Org.). Hidrologia; Ciência e Aplicação. 4 ed. Porto Alegre: Ed. da UFRGS/ABRH, 2009, 943p.

VALE, J. R. B.; BORDALO, C. A. L. Caracterização morfométrica e do uso e cobertura da terra da bacia hidrográfica do Rio Apeú, Amazônia Oriental. Revista Formação, v. 27, n. 51, p. 313-335, 2020.

VILLELA, S. M.; MATTOS, A. Hidrologia Aplicada. São Paulo: Mc Graw Hill, 1975. 


\section{NOTAS DE AUTOR}

\section{CONTRIBUIÇÃO DE AUTORIA}

Jones Remo Barbosa Vale - Concepção. Coleta de dados, Análise de dados, Elaboração do manuscrito, revisão e aprovação da versão final do trabalho

Letícia Soares da Costa - Concepção e elaboração do manuscrito. Coleta de dados Participação ativa da discussão dos resultados; Revisão e aprovação da versão final do trabalho.

Márcia Aparecida da Silva Pimentel - Concepção e elaboração do manuscrito. Coleta de dados Participação ativa da discussão dos resultados; Revisão e aprovação da versão final do trabalho.

\section{FINANCIAMENTO}

Não se aplica.

\section{CONSENTIMENTO DE USO DE IMAGEM}

Não se aplica.

APROVAÇÃO DE COMITÊ DE ÉTICA EM PESQUISA

Não se aplica.

\section{CONFLITO DE INTERESSES}

Não se aplica

\section{LICENÇA DE USO}

Este artigo está licenciado sob a Licença Creative Commons CC-BY. Com essa licença você pode compartilhar, adaptar, criar para qualquer fim, desde que atribua a autoria da obra.

\section{HISTÓRICO}

Recebido em: 03-04-2020

Aprovado em: 31-07-2020 